\title{
5 years after the Kahn's etiquette-based medicine: a brief checklist proposal for a functional second meeting with the patient
}

\author{
Gianluca Castelnuovo ${ }^{1,2 *}$ \\ ${ }^{1}$ Psychology Research Laboratory, Istituto Auxologico Italiano IRCCS, Ospedale San Giuseppe, Verbania, Italy \\ 2 Department of Psychology, Catholic University of Milan, Milan, Italy \\ *Correspondence: gianluca.castelnuovo@auxologico.it
}

Edited by:

Jesus Mora, Hospital Carlos III, Spain

Keywords: etiquette-based medicine, communication, clinical psychology, relationships, strategy

\section{A commentary on}

Etiquette-based medicine

by Kahn, M. W. (2008). N. Engl. J.

Med. 358, 1988-1989. doi: 10.1056/NEJM

p0801863

5 years ago, in a widespread magistral editorial on NEJM (Kahn, 2008), Kahn discussed that medical and clinical education and postgraduate training have to better take into account the so called "etiquette-based medicine." Kahn provided an interesting and practical checklist for physicians and health professionals to improve "etiquette" in the first meeting with a patient:

1. Ask permission to enter the room; wait for an answer.

2. Introduce yourself, showing ID badge.

3. Shake hands (wear glove if needed).

4. Sit down. Smile if appropriate.

5. Briefly explain your role on the team.

6. Ask the patient how he or she is feeling about being in the hospital." (p 1988, Kahn, 2008).

The main goal of this commentary is to provide a brief checklist proposal for a possible second meeting with the patient, particularly when prescriptions and therapeutic indications provided in the first meeting were not totally or partially followed.

In the second meeting please ask yourself the following question: "Where was my behavior lacking in the first meeting? In the "relationship," "communication," or "strategy" level?"

(1) If I was lacking in the relationship, perhaps it means the my patient does not rely on me and I have to recover or rebuild a good relationship showing empathy, professionalism and giving attention to the entire person (the biopsychosocial dimension of each human being) more than to the single pathology problem, allowing patients to continue expressing emotions (Pollak et al., 2007).

(2) If I was lacking in the communication, perhaps it means the I have not well communicated my indications. It could be that I have not used the client's language: for some patients rational and demonstrative communications could be useful, whereas for other ones evocative and persuasive elements are necessary (Bailey, 2006; Pagnini et al., 2009; Castelnuovo, 2013).

(3) If I was lacking in the strategy, perhaps it is also necessary to take into account the patient's type of resistance to change. It is crucial to distinguish among collaborative patients, noncollaborative ones and openly opposing ones: for each category different strategies are required [please find more suggestions in (Bailey, 2006)].

So psychology can deepen and train the relationship, communication, and strategy skills necessary to improve the clinical procedures and results not only in a first etiquette-based meeting, but also during the following etiquettebased treatment sessions (Castelnuovo, 2010).

\section{ACKNOWLEDGMENTS}

Many thanks to Prof. Giorgio Nardone and all the Brief Strategic Therapy School in
Arezzo, Italy, for providing me the checklist and training me in the clinical activity.

\section{REFERENCES}

Bailey, C. (2006). Knowing through changing: the evolution of brief strategic therapy. Therapy Today 17:51.

Castelnuovo, G. (2010). No medicine without psychology: the key role of psychological contribution in clinical settings. Front. Psychol. 1:4. doi: 10.3389/fpsyg.2010.00004

Castelnuovo, G. (2013). Suggestive communication to improve the efficacy of anaesthetic methods in clinical practice. Electronic reply to "Hypnosis as sole anaesthesia for skin tumour removal in a patient with multiple chemical sensitivity." Anaesthesia 68:1454. Available online at: http://www.respond2articles.com/ANA/forums/ permalink/1454/1454/ShowThread.aspx\#1454

Kahn, M. W. (2008). Etiquette-based medicine. N. Engl. J. Med. 358, 1988-1989. doi: 10.1056/NEJMp 0801863

Pagnini, F., Manzoni, G. M., and Castelnuovo, G. (2009). Emotional intelligence training and evaluation in physicians. JAMA 301, 600. doi: 10.1001/ jama.2009.81

Pollak, K. I., Arnold, R. M., Jeffreys, A. S., Alexander, S. C., Olsen, M. K., Abernethy, A. P., et al. (2007). Oncologist communication about emotion during visits with patients with advanced cancer. J. Clin. Oncol. 25, 5748-5752. doi: 10.1200/JCO.2007.12. 4180

Received: 19 September 2013; accepted: 20 September 2013; published online: 23 October 2013

Citation: Castelnuovo G (2013) 5 years after the Kahn's etiquette-based medicine: a brief checklist proposal for a functional second meeting with the patient. Front. Psychol. 4:723. doi: 10.3389/fpsyg.2013.00723

This article was submitted to Psychology for Clinical Settings, a section of the journal Frontiers in Psychology. Copyright (c) 2013 Castelnuovo. This is an openaccess article distributed under the terms of the Creative Commons Attribution License (CC BY). The use, distribution or reproduction in other forums is permitted, provided the original author(s) or licensor are credited and that the original publication in this journal is cited, in accordance with accepted academic practice. No use, distribution or reproduction is permitted which does not comply with these terms. 